\title{
OUTPUT VARIABILITY AND ECONOMIC GROWTH: THE JAPANESE CASE
}

\author{
Stilianos Fountas, Menelaos Karanasos and Alfonso Mendoza
}

Department of Economics, University of Macedonia, Thessaloniki, Greece; and Department of Economics and Related Studies, University of York, York, UK.

\begin{abstract}
We examine the empirical relationship between output variability and output growth using quarterly data for the 1961-2000 period for the Japanese economy. Using three different specifications of GARCH models, namely, Bollerslev's model, Taylor/Schwert's model, and Nelson's EGARCH model, we obtain two important results. First, we find robust evidence that the "in-mean" coefficient is not statistically significant. This evidence is consistent with Speight's (1999) analysis of UK data and implies that output variability does not affect output growth. In other words, this finding supports several real business cycle theories of economic fluctuations. Second, we find no evidence of asymmetry between output variability and growth, a result consistent with Hamori (2000).
\end{abstract}

Keywords: output variability, output growth, GARCH models JEL classification numbers: C22, C51, C52, E32

Correspondence to: Menelaos Karanasos, Department of Economics and Related Studies, University of York, Heslington, York, YO10 5DD, UK; E-mail: mk16@york.ac.uk; fax: + 44-(0)1904-433759; tel: +44-(0) 1904-433799. We would like to thank a joint editor of this journal and two anonymous referees for their helpful comments and suggestions. All remaining errors are our own responsibility. 


\section{INTRODUCTION}

The relationship between the average output growth rate and the variability of output growth has recently attracted the attention of empirical macroeconomists. The growing interest in the subject may have been motivated by the following three factors. First, the richness of economic theories that provide for a variety of possible relationships between the rate of output growth and its variability. Second, developments in the econometrics of time series techniques that facilitate the measurement of the variability of an economic variable. Third, the variety of empirical results to date concerning the direction of the impact of output variability on output growth (e.g., Caporale and McKiernan, 1996, Speight, 1999, Henry and Olekalns, 2002).

Our empirical approach attempts to fill a gap in the literature in a number of ways. First, we employ quarterly GDP data on Japan, a member of the G3, and a country that has experienced significant variability in output growth over the last 40 years. This variability is exemplified by the frequent occurrence of negative output growth rates during the 1990s. Second, we use three alternative GARCH model specifications in dealing with the measurement issue of output growth variability: Bollerslev's (1986) model, Taylor (1988)/Schwert's (1990) model, and Nelson's (1991) exponential GARCH model. Third, we allow for three different specifications of the "risk premium": the conditional variance, the conditional standard deviation, and the natural log of the conditional variance. Fourth, we examine the possibility of asymmetry in output variability.

The paper is structured as follows. Section II analyses the economic theories that claim to examine the possible impact of output growth variability on output growth and it offers a short review of the relevant literature. Section III discusses the GARCH models we employ in our empirical analysis. Section IV presents our empirical results. Finally, Section $\mathrm{V}$ provides our main conclusions and compares them with those found in recent literature.

\section{THEORY AND EMPIRICAL EVIDENCE}

Given the absence of a theoretical consensus, the anticipated relationship between output variability and economic growth remains an empirical issue. Macroeconomic theory offers three possible scenarios regarding the impact of output variability on output growth. One is the possibility of independence between output variability and growth. In other words, the determinants of the two variables are different from each other. According to some business cycle models, output fluctuations around the natural rate are due to price misperceptions in response to monetary shocks. On the other hand, changes in the growth rate of output arise from real factors such as technology (Friedman, 1968).

(C) Blackwell Publishing Ltd and the Board of Trustees of the Bulletin of Economic Research 2004. 
The scenario of a negative association between output variability and average growth goes back to Keynes (1936), who argued that entrepreneurs, when estimating the return on their investment, take into consideration the fluctuations in economic activity. The larger the output fluctuations, the higher the perceived riskiness of investment projects and, hence, the lower the demand for investment and output growth. A similar result is obtained by the literature on sunspot equilibria (Woodford, 1990). According to Bernanke (1983) and Pindyck (1991), the negative relationship between output volatility and growth arises from investment irreversibilities at the firm level.

Finally, the positive impact of output variability on growth could be justified by the following two economic theories. More income variability (uncertainty) would lead to a higher savings rate (Sandmo, 1970) and hence, according to Solow's (1956) neoclassical growth theory, a higher equilibrium rate of economic growth. This argument has been advanced by Mirman (1971). The alternative explanation is due to Black (1987) and is based on the hypothesis that investments in riskier technologies will be pursued only if the expected return on these investments (average rate of output growth) is large enough to compensate for the extra risk. As real investment takes time to materialize, such an effect would be more likely to obtain in empirical studies utilizing low-frequency data.

The empirical evidence to date on the association between output variability and output growth is mixed. Early studies employed cross section (Kormendi and Meguire, 1985) or pooled data (Grier and Tullock, 1989) and found evidence for a positive association. More recent studies use time series techniques (GARCH models) to measure output variability (Caporale and McKiernan, 1996, 1998; Speight, 1999). The first two papers use UK and US data, respectively, and find a positive association between output variability and growth, whereas the last paper uses UK data and finds no association. Henry and Olekalns (2002) find evidence in favour of a negative association using post-war real GDP data for the United States. Finally, Bhar and Hamori (2003) examine the relationship between output volatility and economic growth for Japan using a Markov switching model.

Given the inconclusiveness of the existing empirical time series literature and the sparsity of evidence using international data, we aim to provide more robust evidence using several approaches to model the interdependence between output variability and growth and to measure output variability.

\section{GARCH MODELS}

We proxy output variability by the conditional variance of the output growth series. In our empirical work we estimate several univariate

(C) Blackwell Publishing Ltd and the Board of Trustees of the Bulletin of Economic Research 2004. 
GARCH-in-mean models for output growth. These models allow us to simultaneously estimate equations for the conditional mean and variance of output growth.

Let $y_{t}$ represent output growth in period $t$, which follows an autoregressive (AR) process augmented by a "risk premium" defined in terms of volatility

$$
\Phi(L) y_{t}=\phi_{0}+\delta g\left(h_{t}\right)+\varepsilon_{t},
$$

with

$$
\Phi(L)=1-\sum_{i=1}^{p} \phi_{i} L^{i}
$$

and

$$
\varepsilon_{t}=e_{t} \sqrt{h_{t}}
$$

where $\left\{e_{t}\right\}$ is a sequence of independent, identically distributed random variables with mean zero and variance 1 , and $h_{t}$ denotes the conditional variance of output growth.

Furthermore, we need to choose the form in which the timevarying variance enters the specification of the mean to determine the "risk premium". This is a matter of empirical evidence. Caporale and McKiernan (1996) found that the logarithm of the conditional variance worked better in their estimation of the time-varying risk premia. However, as noted by Pagan and Hong (1991), the use of $\ln \left(h_{t}\right)$ is possibly unsatisfactory. First, for $h_{t}<1, g\left(h_{t}\right)<0$, which leads to a negative sign for the "risk premium". Second, as $h_{t} \rightarrow 0$, conditional volatility in logs becomes very large and, therefore, the implicit relationship between conditional volatility and $y_{t}$ is overstated. As a result, Speight (1999) assumed linearity between the conditional variance and the growth of output. Alternatively, one can use the conditional standard deviation as a regressor in the conditional mean (Henry and Olekalns, 2002). Therefore, in the empirical results that follow we employ all three specifications for the functional form of the "risk premium". That is, we use $g\left(h_{t}\right)=h_{t}, g\left(h_{t}\right)=\sqrt{h_{t}}$, or $g\left(h_{t}\right)=\ln \left(h_{t}\right)$.

Moreover, for the variance equation we use three alternative asymmetric GARCH processes. Firstly, Bollerslev's (1986) GARCH(1,1) model extended by the inclusion of a leverage term to allow for the modelling of asymmetric effects of positive and negative shocks

$$
(1-\beta L) h_{t}=\omega+\alpha\left(\left|\varepsilon_{t-1}\right|+\gamma \varepsilon_{t-1}\right)^{2},
$$

where $\omega, \alpha>0, \beta \geq 0$, and $|\gamma|<1$.

(C) Blackwell Publishing Ltd and the Board of Trustees of the Bulletin of Economic Research 2004. 
Secondly, Taylor (1988)/Schwert's (1990) model, where the conditional standard deviation follows a $\operatorname{GARCH}(1,1)$ process extended by the inclusion of a leverage term

$$
(1-\beta L) \sqrt{h_{t}}=\omega+\alpha\left(\left|\varepsilon_{t-1}\right|+\gamma \varepsilon_{t-1}\right),
$$

where $\omega, \alpha>0, \beta \geq 0$, and $|\gamma|<1$.

Thirdly, an exponential GARCH(1,1) model, where the logarithm of the conditional variance follows an $\operatorname{ARMA}(1,1)$ process

$$
(1-\beta L) \ln \left(h_{t}\right)=\omega+\alpha\left(\left|e_{t-1}\right|+\gamma e_{t-1}\right) .
$$

It should be noted that the majority of the existing empirical literature has used only Bollerslev's (1986) model in analysing the output growth/ variability nexus. One exception is Hamori (2000), which used the EGARCH and Threshold GARCH (TGARCH) models. However, he only tested for the asymmetric relationship between output growth and its variability and did not use an "in-mean" term. Another exception is Henry and Olekalns (2002), who used the TGARCH model. Our consideration of all three models discussed in this section provides for a more systematic analysis of the issue at hand.

\section{EMPIRICAL RESULTS}

\section{IV.1 Data}

We use seasonally adjusted time series data on Japanese GDP obtained from the OECD Main Economic Indicators database. The sample period is from the first quarter of 1961 to the second quarter of $2000 .{ }^{1}$ Real output growth $\left(y_{t}\right)$ is defined as the difference in the $\log$ of GDP $\left[y_{t}=\log \left(\mathrm{GDP}_{t} / \mathrm{GDP}_{t-1}\right)\right]$ and is plotted in Figure 1. We test for the stationarity properties of our data using the Augmented Dickey-Fuller (ADF) and Phillips-Perron (PP) tests. The results of these tests are reported in Table 1 and imply that we can treat the growth rate of GDP as a stationary process.

\section{IV.2 Empirical application}

We estimate various AR-GARCH-in-mean (AR-GARCH-M) models using the Berndt et al. (1974) numerical optimization algorithm (BHHH) to obtain the maximum likelihood estimates of the parameters. For

\footnotetext{
${ }^{1}$ Caporale and McKiernan (1996) and Speight (1999) use monthly data, Henry and Olekalns (2002) use quarterly data, and Caporale and McKiernan (1998) employ annual data. As mentioned in Section II, the use of low-frequency data (quarterly) allows us to perform a more appropriate test of the Black (1987) hypothesis.
}

(C) Blackwell Publishing Ltd and the Board of Trustees of the Bulletin of Economic Research 2004. 


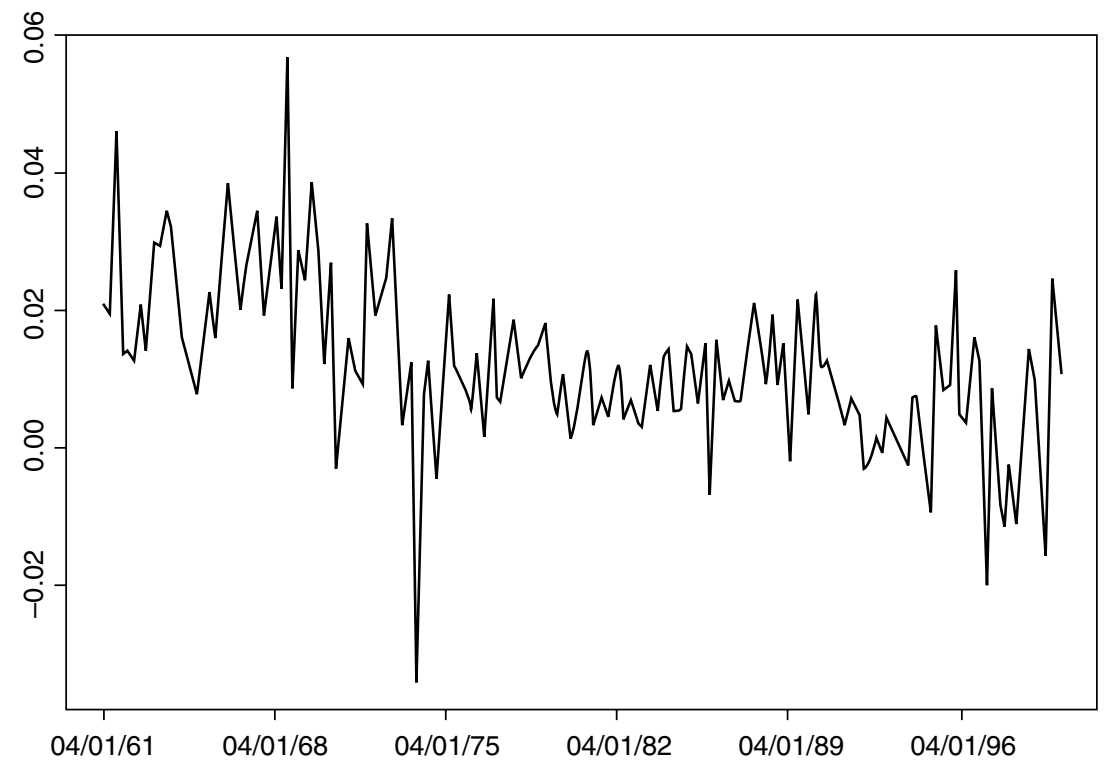

Fig. 1. REAL GROWTH RATE: JAPAN, 1961:Q1-2000:Q2

purposes of robustness and comparison, all three conditional variance specifications, namely, Bollerslev's (1986) GARCH, Nelson's (1991) EGARCH, and Taylor (1988)/Schwert's (1990) GARCH, which were presented in Section III, are considered further in an AR-GARCH-M context. In addition, we use one of $h_{t}, \sqrt{h_{t}}$ and $\ln \left(h_{t}\right)$ each time as a regressor in the mean equation to capture the in-mean effect. The Schwarz Information Criterion (SIC) suggests the choice of AR(3) models for the conditional mean. In our empirical analysis, the question of whether or not real growth rates in GDP display any asymmetry in volatility is also explored. In all three versions of the GARCH-type models, the asymmetry coefficient $(\gamma)$ is statistically insignificant. Therefore, the empirical

TABLE 1

Unit root tests

\begin{tabular}{lr}
\hline$A D F$ & \multicolumn{1}{c}{$P P$} \\
\hline-4.623 & -11.062 \\
\hline
\end{tabular}

Notes: ADF (PP) is the Augmented Dickey-Fuller (Phillips-Perron) test statistic. A constant and four lagged differenced terms are used for the ADF test. The MacKinnon critical value for rejection of the hypothesis of a unit root at 0.01 significance level is -3.45 .

(C) Blackwell Publishing Ltd and the Board of Trustees of the Bulletin of Economic Research 2004. 
results for $\gamma$ (not reported here) do not support the existence of asymmetry between the volatility and growth rates in the data.

Panel A of Table 2 reports parameter estimates for the four alternative Bollerslev's (1986) GARCH $(1,1)$ models. The fourth model restricts the

\section{TABLE 2}

Real Growth Rate: Japan, 1961:Q1-2000:Q2

Panel A: AR(3)-Bollerslev's GARCH(1,1) Models.

\begin{tabular}{ccccc}
\hline & $h_{t}$ & $\sqrt{h_{t}}$ & $\ln \left(h_{t}\right)$ & - \\
$\delta$ & 22.130 & 0.512 & 0.002 & - \\
& $(16.960)$ & $(0.331)$ & $(0.002)$ & - \\
$\omega$ & $3 \times 10^{-6}$ & $3 \times 10^{-6}$ & $3 \times 10^{-6}$ & $3 \times 10^{-6}$ \\
& $\left(3 \times 10^{-6}\right)$ & $\left(3 \times 10^{-6}\right)$ & $\left(3 \times 10^{-6}\right)$ & $\left(3 \times 10^{-6}\right)$ \\
$\alpha$ & 0.128 & 0.139 & 0.152 & 0.135 \\
& $(0.073)$ & $(0.078)$ & $(0.085)$ & $(0.082)$ \\
$\beta$ & 0.855 & 0.848 & 0.837 & 0.847 \\
& $(0.076)$ & $(0.078)$ & $(0.083)$ & $(0.081)$ \\
\hline
\end{tabular}

Panel B: AR(3)-Nelson's EGARCH(1,1) Models.

\begin{tabular}{ccccc}
\hline & $h_{t}$ & $\sqrt{h_{t}}$ & $\ln \left(h_{t}\right)$ & - \\
$\delta$ & 25.880 & 0.532 & 0.003 & - \\
& $(19.320)$ & $(0.372)$ & $(0.002)$ & - \\
& -0.581 & -0.569 & -0.623 & -0.554 \\
& $(0.438)$ & $(0.431)$ & $(0.465)$ & $(0.392)$ \\
& 0.252 & 0.263 & 0.281 & 0.258 \\
$\beta$ & $(0.126)$ & $(0.131)$ & $(0.130)$ & $(0.139)$ \\
& 0.958 & 0.960 & 0.956 & 0.962 \\
& $(0.043)$ & $(0.041)$ & $(0.045)$ & $(0.037)$ \\
\hline
\end{tabular}

Panel C: AR(3)-Taylor/Schwert's GARCH(1,1) Models.

\begin{tabular}{ccccc}
\hline & $h_{t}$ & $\sqrt{h_{t}}$ & $\ln \left(h_{t}\right)$ & - \\
$\delta$ & 14.450 & 0.449 & 0.003 & - \\
& $(13.890)$ & $(0.322)$ & $(0.002)$ & - \\
$\omega$ & 0.001 & 0.001 & 0.001 & 0.001 \\
& $(0.001)$ & $(0.001)$ & $(0.001)$ & $(0.001)$ \\
$\alpha$ & 0.153 & 0.149 & 0.156 & 0.152 \\
& $(0.072)$ & $(0.070)$ & $(0.071)$ & $(0.075)$ \\
$\beta$ & 0.786 & 0.791 & 0.784 & 0.768 \\
& $(0.074)$ & $(0.069)$ & $(0.068)$ & $(0.085)$ \\
$d^{*}$ & 0.011 & 0.011 & 0.012 & 0.014 \\
& $(0.006)$ & $(0.006)$ & $(0.006)$ & $(0.008)$
\end{tabular}

Notes: Table 2 reports parameter estimates of the various GARCH(1,1)-type of models. The numbers in parentheses are standard errors. * The dummy variable in the conditional standard deviation equation takes the value one on the following quarters: 1968:Q4 and 1974:Q1.

(C) Blackwell Publishing Ltd and the Board of Trustees of the Bulletin of Economic Research 2004. 
"in-mean" effect to zero. As shown in the results, for each of the four alternative Bollerslev's (1986) GARCH models, the GARCH term is highly statistically significant, whereas the ARCH term is significant at the 10 percent level or better. The sum of the ARCH and GARCH terms (which is a measure of the persistence of shocks to output volatility) ranges between 0.982 and 0.989 . Further, the estimated coefficients of $\ln \left(h_{t}\right), \sqrt{h_{t}}$, and $h_{t}$ are positive but statistically insignificant at the 10 percent level or better. Panel B of Table 2 shows the empirical results for the four alternative $\operatorname{EGARCH}(1,1)$ models. For each of the four conditional variance functions, all (ARCH and $\mathrm{GARCH})$ parameter estimates are highly statistically significant. Further, the three "in-mean" coefficients are not significant at the 10 percent level or better.

For the purpose of comparison, we also estimate four alternative Taylor (1988)/Schwert's (1990) GARCH(1,1) models. It should also be noted that this parameterization yields a measure of the persistence of shocks to the conditional standard deviation which is higher than one. Therefore, we re-estimate our Taylor/Schwert's models including a dummy variable as an exogenous variable in the conditional standard deviation equation. Panel $\mathrm{C}$ of Table 2 presents our results. The ARCH and GARCH terms are highly significant. All three "in-mean" coefficients are not significant at the 10 percent level or better.

Table 3 reports some diagnostics on the residuals of the above three groups of models and some model specification tests. The Ljung-Box Q test statistics (12 lags) for the standardized residuals and the squared standardized residuals are lower than the 5 percent critical value, thus indicating no further first or second-order serial dependence. The insignificant Shapiro-Wilk (SW) test statistic confirms the presence of conditional normality. The plain GARCH models are chosen on the basis of the minimization of the SIC. Further, a likelihood ratio test cannot reject the plain GARCH model in favour of the "in-mean" models at the 5 percent significance level or better. Hence, on the basis of these diagnostics we can conclude that the estimated models are not subject to misspecification.

\section{CONCLUSIONS}

We have employed Japanese GDP quarterly data for the 1961-2000 period to examine the empirical relationship between output variability and output growth. Our empirical approach uses three alternative specifications of GARCH models, namely, Bollerslev's (1986) model, Taylor (1988)/Schwert's (1990) model, and Nelson's (1991) EGARCH model. We obtain two important results. First, we find robust evidence that the "in-mean" coefficient is not statistically significant. This evidence is consistent with Speight's (1999) analysis of UK data, implying

(C) Blackwell Publishing Ltd and the Board of Trustees of the Bulletin of Economic Research 2004. 
TABLE 3

Information criteria, residual diagnostics and likelihood ratio tests Panel A: AR(3)-Bollerslev's GARCH(1,1) Models.

\begin{tabular}{lcccc}
\hline & $h_{t}$ & $\sqrt{h_{t}}$ & $\ln \left(h_{t}\right)$ & - \\
SIC & -959.301 & -959.733 & -960.115 & -961.241 \\
SW & 0.982 & 0.982 & 0.981 & 0.983 \\
& {$[0.540]$} & {$[0.517]$} & {$[0.471]$} & {$[0.576]$} \\
Q(12) & 14.400 & 14.510 & 14.670 & 15.810 \\
& {$[0.276]$} & {$[0.269]$} & {$[0.260]$} & {$[0.200]$} \\
$\mathrm{Q}^{2}(12)$ & 4.933 & 5.115 & 5.378 & 4.860 \\
& {$[0.960]$} & {$[0.954]$} & {$[0.944]$} & {$[0.963]$} \\
\hline LR & 3.118 & 3.550 & 3.932 & - \\
& {$[0.077]$} & {$[0.059]$} & {$[0.047]$} & \\
\hline
\end{tabular}

Panel B: AR(3)-Nelson's EGARCH(1,1) Models.

\begin{tabular}{lcccc}
\hline & $h_{t}$ & $\sqrt{h_{t}}$ & $\ln \left(h_{t}\right)$ & - \\
SIC & -962.676 & -962.966 & -963.039 & -964.585 \\
SW & 0.985 & 0.985 & 0.984 & 0.985 \\
& {$[0.726]$} & {$[0.692]$} & {$[0.653]$} & {$[0.707]$} \\
Q(12) & 14.080 & 14.340 & 14.560 & 15.390 \\
& {$[0.295]$} & {$[0.279]$} & {$[0.266]$} & {$[0.221]$} \\
$\mathrm{Q}^{2}(12)$ & 6.014 & 6.139 & 6.394 & 5.632 \\
& {$[0.915]$} & {$[0.909]$} & {$[0.895]$} & {$[0.934]$} \\
\hline LR & 3.148 & 3.438 & 3.51 & \\
& {$[0.076]$} & {$[0.064]$} & {$[0.061]$} & \\
\hline
\end{tabular}

Panel C: AR(3)-Taylor/Schwert's GARCH(1,1) Models.

\begin{tabular}{lcccc}
\hline & $h_{t}$ & $\sqrt{h_{t}}$ & $\ln \left(h_{t}\right)$ & - \\
SIC & -971.102 & -972.068 & -972.947 & -974.575 \\
SW & 0.986 & 0.987 & 0.987 & 0.987 \\
& {$[0.791]$} & {$[0.809]$} & {$[0.806]$} & {$[0.834]$} \\
Q(12) & 12.980 & 12.730 & 12.900 & 14.220 \\
& {$[0.370]$} & {$[0.389]$} & {$[0.376]$} & {$[0.287]$} \\
$\mathrm{Q}^{2}(12)$ & 7.487 & 8.284 & 9.456 & 7.647 \\
& {$[0.824]$} & {$[0.763]$} & {$[0.664]$} & {$[0.812]$} \\
\hline LR & 1.180 & 2.148 & 3.026 & - \\
& {$[0.277]$} & {$[0.143]$} & {$[0.082]$} & \\
\hline
\end{tabular}

Notes: SIC is the Schwarz Information Criterion. SW is the Shapiro-Wilk test for normality. Q(12) and $\mathrm{Q}^{2}(12)$ are the Ljung-Box statistics for 12th-order serial correlation in the standardized residuals and their squares, respectively. The numbers in brackets are $p$-values. $\mathrm{LR}$ is the value of the following likelihood ratio (LR) test: $\mathrm{LR}=2 \times\left[\mathrm{ML}_{\mathrm{u}}-\right.$ $M L_{R}$, where $M L_{u}$ and $M L_{R}$ denote the maximum log likelihood values of the unrestricted (in-mean) and restricted model, respectively. 
that output variability does not affect output growth. In other words, this finding supports several real business cycle theories of economic fluctuations. Our second result is that we find no evidence of asymmetry between output variability and growth, a result consistent with Hamori (2000).

\section{REFERENCES}

Bernanke, B. (1983). 'Irreversibility, uncertainty, and cyclical investment', Quarterly Journal of Economics, 98, pp. 85-106.

Berndt, E., Hall, B., Hall, R. and Hausman, J., (1974). 'Estimation and inference in nonlinear structural models', Annals of Economic and Social Measurement, 3, pp. 653-65.

Bhar, R. and Hamori, S., (2003). 'Alternative characterisation of the volatility in the growth rate of real GDP', Japan and the World Economy, 15, pp. 223-31.

Black, F. (1987). Business Cycles and Equilibrium. New York: Basil Blackwell.

Bollerslev, T. (1986). 'A generalized autoregressive conditional heteroskedasticity', Journal of Econometrics, 31, pp. 307-27.

Caporale, T. and McKiernan, B. (1998). 'The Fischer Black hypothesis: Some time-series evidence', Southern Economic Journal, 64, pp. 765-71.

Caporale, T. and McKiernan, B. (1996). 'The relationship between output variability and growth: Evidence from post-war UK data', Scottish Journal of Political Economy, 43, pp. 229-36.

Friedman, M. (1968). 'The role of monetary policy', American Economic Review, 58, pp. $1-17$.

Grier, K. and Tullock, G. (1989). 'An empirical analysis of cross-national economic growth 1951-1980', Journal of Monetary Economics, 24, pp. 259-76.

Hamori, S. (2000). 'Volatility of real GDP: Some evidence from the United States, the United Kingdom and Japan', Japan and the World Economy, 12, pp. 143-52.

Henry, Ó. and Olekalns, N. (2002). 'The effect of recessions on the relationship between output variability and growth', Southern Economic Journal, 68, pp. 683-92.

Keynes, J. M. (1936). The General Theory of Employment, Interest, and Money. London: Macmillan.

Kormendi, R. and Meguire, P. (1985). 'Macroeconomic determinants of growth: Cross-country evidence', Journal of Monetary Economics, 16, pp. 141-63.

Mirman, L. (1971). 'Uncertainty and optimal consumption decisions', Econometrica, 39, pp. 179-85.

Nelson, D. (1991). 'Conditional heteroskedasticity in asset returns: A new approach', Econometrica, 59, pp. 347-70.

Pagan, A. and Hong, Y. S. (1991). 'Nonparametric estimation and the risk premium', in Barnett, W. A., Powell, J. and Tauchen, G. (eds.), Nonparametric and Semiparametric Methods in Econometrics and Statistics, Cambridge: Cambridge University Press, pp. 51-75.

Pindyck, R. (1991). 'Irreversibility, uncertainty, and investment', Journal of Economic Literature, 29, pp. 1110-1148.

(C) Blackwell Publishing Ltd and the Board of Trustees of the Bulletin of Economic Research 2004. 
Sandmo, A. (1970). 'The effect of uncertainty on saving', Review of Economic Studies, 37, pp. 353-60.

Schwert, W. (1990). 'Stock volatility and the crash of '87', Review of Financial Studies, 3, pp. 77-102.

Solow, R. (1956). 'A contribution to the theory of economic growth', Quarterly Journal of Economics, 70, pp. 65-94.

Speight, A. (1999). 'UK output variability and growth: Some further evidence', Scottish Journal of Political Economy, 46, pp. 175-84.

Taylor, S. (1988). Modelling Financial Time Series. New York: Wiley.

Woodford, M. (1990). 'Learning to believe in sunspots', Econometrica, 58, pp. 277-307. 
